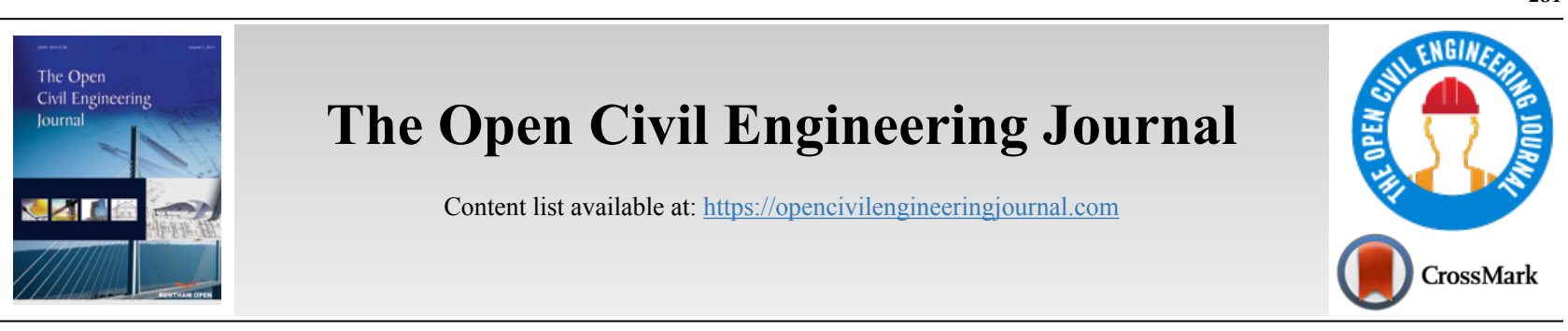

RESEARCH ARTICLE

\title{
Effect of Fatty Acids Addition into Backfilling Material in Over-cutting Area on Improvement of Lubrication Performance for Pipe Jacking
}

\author{
Kazuki Maehara ${ }^{1}$, Takashi Sasaoka ${ }^{1, *}$, Akihiro Hamanaka $^{1, *}$ and Hideki Shimada ${ }^{1}$ \\ ${ }^{1}$ Department of Earth Resources Engineering, Faculty of Engineering, Kyushu University 744 Motooka, Nishi-ku, Fukuoka City, 819-0395, Japan
}

\begin{abstract}
:
Background:

The demand for underground space utilization using pipe jacking method is increased especially in the congested urban area.

Methods:

In the method, the over-cutting area is formed between pipes and surrounding soils in order to smoothly construct underground pipelines. The backfilling materials as a lubricant are injected into the over-cutting area during the constructions in order to reduce the friction resistance and to sustain the surrounding ground against the overburden pressure. Therefore, the performance of lubrication for backfilling material is significant. In this study, the fatty acids are added into the backfilling material to improve the lubrication performance.

Conclusion:

Laboratory studies have shown that the bleeding rate is reduced with the increase in addition ratio of fatty acids, however, the excess addition may cause the shrinkage of the backfilling material due to the effect of water absorption from the pipe. Additionally, $3 \%$ addition of fatty acids into the conventional backfilling material is the most effective to reduce the thrust for pipe jacking based on the results of the direct shear tests.
\end{abstract}

Keywords: Lubricant, Fatty acid, Jacking thrust, Pipe jacking method, Moisture balance, Backfilling material.

\begin{tabular}{|l|l|l|l} 
Article History & Received: October 13, 2019 & Revised: December 16, 2019 & Accepted: December 17, 2019
\end{tabular}

\section{INTRODUCTION}

In recent years, infrastructure utilizing the underground space has actively constructed along with the overcrowding of urban areas. In the development of the underground infrastructure, the pipe jacking method is applied in many cases because the area occupied on the ground is small and the noise of the surrounding is minimized $[1,2]$. In the pipe jacking method, the excavator is attached to the tip of the pipes, and the pipeline is laid by pushing pipes through a hydraulic jack behind, while excavating underground $[3,4]$. In the method, the over-cutting area is formed between the pipes and surrounding soils in order to smoothly construct underground pipelines. Additionally, the backfilling materials are injected into the over-cutting area as a lubricant to avoid contact with the surrounding soil and to reduce the friction $[5,6]$.

However, it has been reported that the thrust has increased

\footnotetext{
* Address correspondence to this author at the Department of Earth Resources Engineering, Faculty of Engineering, Kyushu University 744 Motooka, Nishi-ku, Fukuoka City, Japan, 819-0395; Fax: +81-92-8023368; Tel: +81-92-8023331; E-mail: hamanaka@mine.kyushu-u.ac.jp
}

when the longer construction period is needed because the pipes contact the surrounding soils due to the compression of the lubricant by a load of overburden [7]. Moreover, the increase in jacking force at the restart due to the interruption of jacking during the night or a weekend was also reported $[8,9]$. Several pieces of research indicated the importance of lubricants to be injected between the pipes and surrounding soil to reduce the friction resistance [10, 11]. Yang et al. (2018) discussed the improvement of the lubrication performance by adding some treating agents for the construction in expansive formations [9]. Shimada et al. (2014) developed a backfilling material which has functions to overcome groundwater pressure and stabilize the over-cutting area [12]. However, Doi and Ino (2012) indicate that the development of backfilling material which has both functions, the reduction of thrust, and the support of surrounding ground, is still a challenge to allow greater jacking lengths [13].

Therefore, new backfilling material to reduce the friction between the pipes and the lubricant surface and to support the surrounding ground has to be developed. It is considered that 
the addition of fatty acids into the backfilling materials can reduce friction since its oils and fats act as a lubricant on the surface [14]. In this report, the effect of adding fatty acids into backfilling material is investigated in terms of a backfilling material for the pipe jacking method in the over-cutting area.

\section{METHODS}

\subsection{The Moisture Balance of Backfilling Material in Over- cutting Area}

The bleeding test was carried out according to ASTM Standard D 5084-03. As shown in Fig. (1), the prepared backfilling material about $300 \mathrm{~mL}$ was added to the mold. The height of the separation surface of the sample and water was measured with the elapsed time [15]. In the moisture adsorption test, the backfilling material was placed on a fully dried pipe and pressurized at $90 \mathrm{kPa}$ for 20 minutes (Fig. 2). Similar to the pipes, a sample dried mortar with water cement ratio of $50 \%$ was used. Portland cement is used as the cement. The pipe material should affect the capacity of water absorption, but the pipe material is out of our focus in this study in order to obtain fundamental data to absorb water from the mortar. After pressurization, the water content ratio of the simulated pipes was measured. The water adsorption amount of the simulated pipes was calculated. The solution mixing fresh water $\left(363.9 \mathrm{~cm}^{3}\right)$ and powder, bentonite solution $\left(450.0 \mathrm{~cm}^{3}\right)$ and silicate soda $\left(50.0 \mathrm{~cm}^{3}\right)$ is prepared, and we made the backfilling material by mixing them. The formulation of powder is shown in Table $\mathbf{1}$.

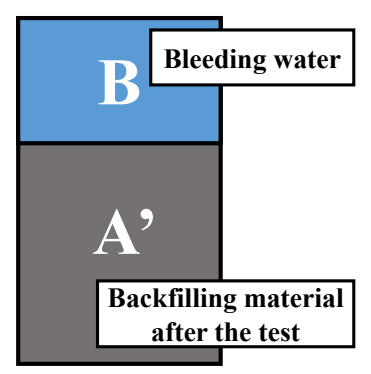

Bleeding rate $(\%)=$ Volume $B /\left(\right.$ Volume $A^{\prime}+$ Volume $\left.B\right) \times 100$

Fig. (1). Performance scheme of the bleeding test.

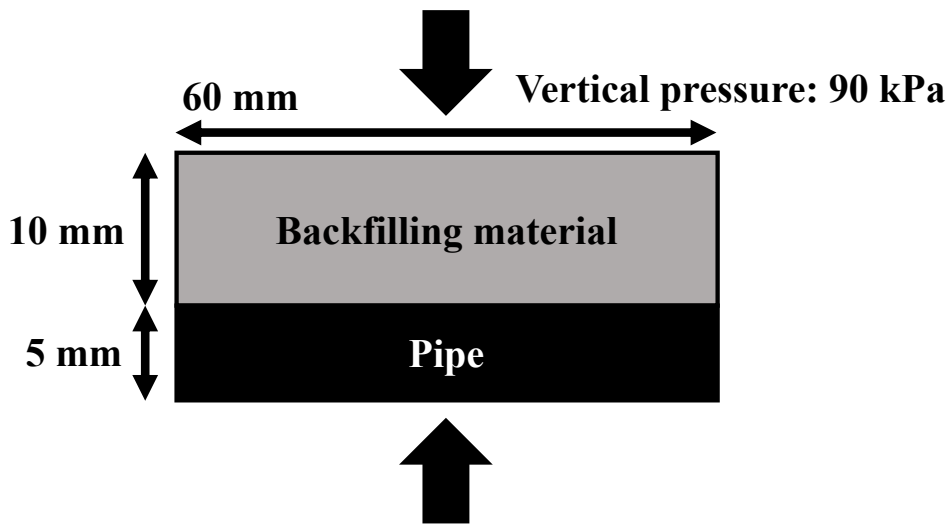

Fig. (2). Scheme of the moisture adsorption test of the pipes.

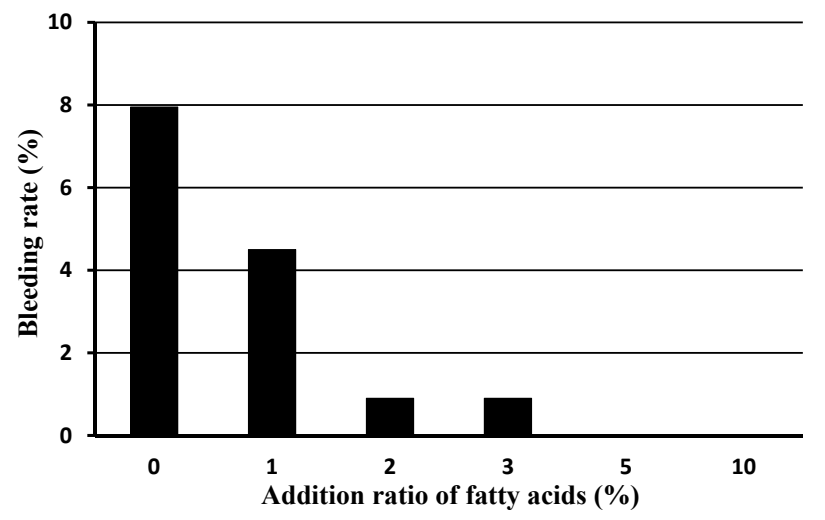

Fig. (3). Dependency of the bleeding rate from the percentage of fatty acids in the backfilling material. 
Table 1. Formulation of powder (backfilling material).

\begin{tabular}{|c|c|}
\hline Material name & Quantity (kg) \\
\hline Slag & 70.0 \\
\hline Cement & 30.0 \\
\hline Fly ash & 140.0 \\
\hline Plaster & 20.0 \\
\hline Bentonite & 40.0 \\
\hline Addition agent & 8.50 \\
\hline Total & 308.5 \\
\hline
\end{tabular}

\subsection{Results and Discussion}

Fig. (3) shows the results of the bleeding test. From Fig. (3), the value of the bleeding rate decreases with the addition of fatty acids. The bleeding phenomenon is caused by the density difference between water and powder [16]. That is, it is considered that the bleeding rate decreases with the addition of fatty acids since they have a lower density than other materials. Fig. (4) shows the moisture adsorption amount per surface area of the simulated pipes. Regardless of the addition ratio of fatty acids, it is found that the simulated pipes adsorb moisture after the test. Based on the above results, the moisture balance of the generation of the bleeding water and the moisture adsorption of the pipes is calculated when a pipe diameter is $3,000 \mathrm{~mm}$ (Fig. 5) [17]. From Fig. (5), it is concerned that when the backfilling material with a fatty acid addition ratio of $5 \%$ or more is applied, the volume decreases due to the escape of water from the backfilling material. It makes it difficult to maintain the volume of the over-cutting area. It was found that the addition ratio of fatty acids needs to be less than $5 \%$.

\section{STUDY ON REDUCTION OF THRUST WITH THE ELAPSED TIME}

During the construction of the pipe jacking method, construction may be interrupted due to changes in geological conditions. In this case, it has been reported that the thrust has increased after a restart of construction. Here, it is considered that the function of lubricant to reduce the thrust can be achieved by adding fatty acids to the existing backfilling materials. Therefore, in order to investigate the effect of adding fatty acids to reduce thrust, the direct shear test was conducted under the different mixing ratios of fatty acids, depth, and pipe jacking speed.

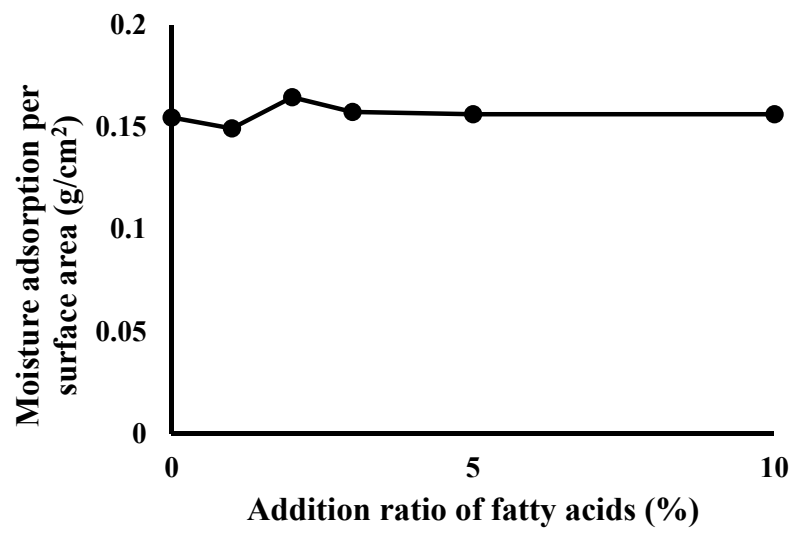

Fig. (4). Dependency of the moisture adsorption per surface area from the percentage of fatty acids in the backfilling material.

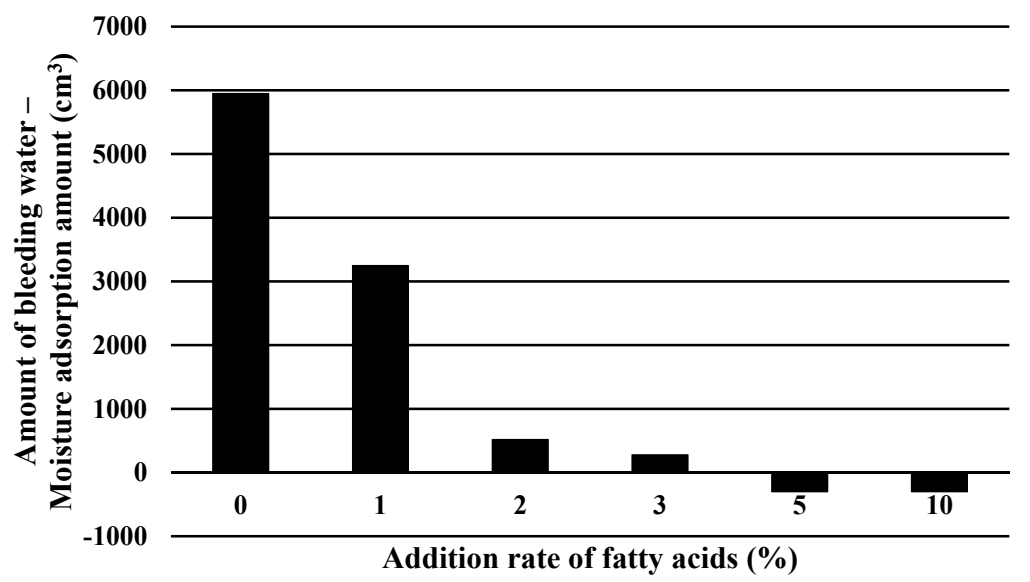

Fig. (5). Moisture balance of the generation of the bleeding water and the moisture adsorption depending on the addition of the ratio of fatty acids (Pipe diameter of $3,000 \mathrm{~mm}$ ). 


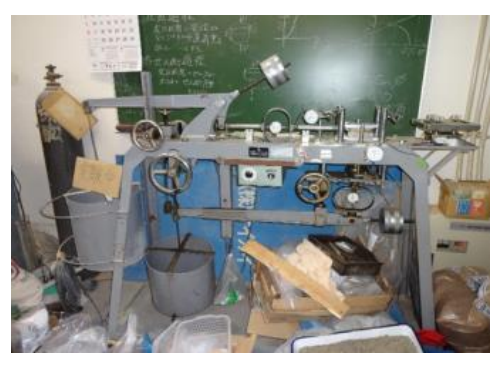

(a) Experimental equipment

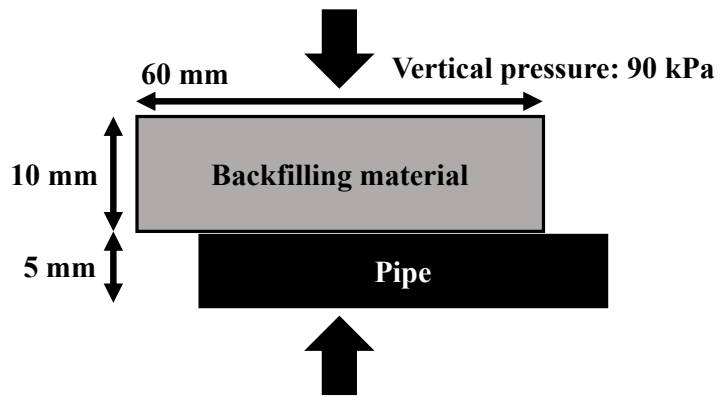

(b) Scheme of the direct shear test.

Fig. (6). Direct shear test to evaluate the thrust of pipe jacking.

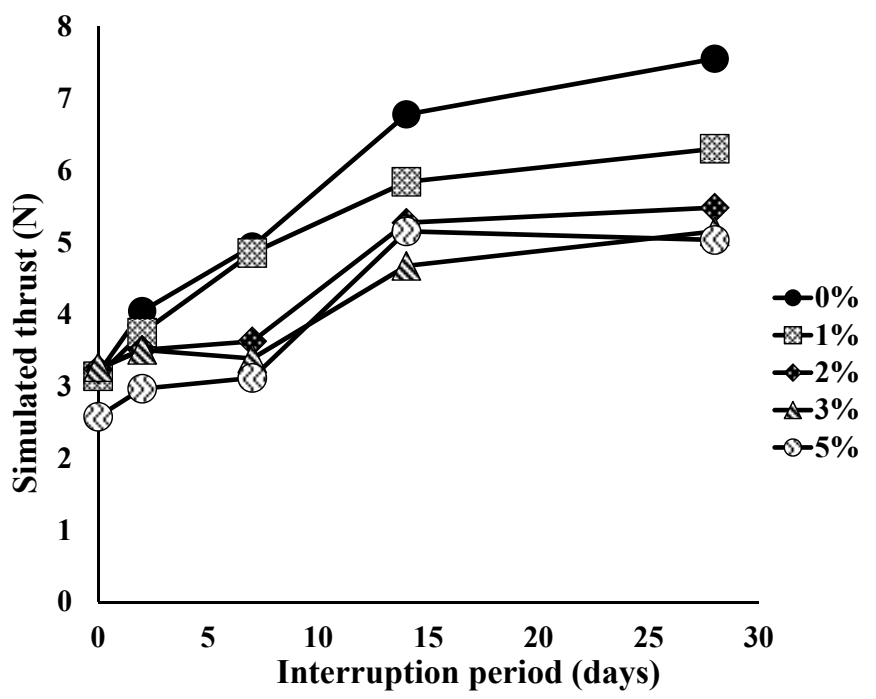

Fig. (7). Dependency of thrust from the interruption period and percentage of fatty acids.

\subsection{Experimental Method}

Fig. (6a and b ) show the experimental equipment and the scheme of the direct shear test. In order to discuss the effectiveness of adding fatty acids to reduce the thrust, we measured the shear stress between the simulated pipe and the backfilling material when the shear displacement was $6 \mathrm{~mm}$ because the clear stress peak cannot be found in the test.

\section{RESULTS AND DISCUSSION}

In order to investigate the influence of the construction interruption period on the thrust at the resumption of construction, we set the curing period to 0 (12 hours), 2, 7, 14 and 28 days. Assuming a construction depth of $5 \mathrm{~m}$, constantly pressurizing the vertical pressure of $90 \mathrm{kPa}$ was adopted during the test. In addition, the pipe jacking speed was assumed to be $1.0 \times 10^{-2} \mathrm{~cm} / \mathrm{s}$. The test results are shown in Fig. (7). It can be seen that the thrust increases with the elapse of the interruption period when the fatty acids addition ratio is $0 \%$ (existing) and $1 \%$. On the other hand, the fatty acids addition ratio of $2 \%$ or more is effective to reduce the thrust until the 7 days since the thrust is constant. Furthermore, even when the interruption period is 14 days or more, the larger the fatty acids addition ratio, the smaller the thrust. From these results, it is confirmed that the thrust can be reduced until 7 days of interruption by adding $2 \%$ or more fatty acids to the backfilling material.

In order to investigate the influence of the depth of construction on the thrust at the resumption of construction, the test was conducted under the condition of $45 \mathrm{kPa}$ and $90 \mathrm{kPa}$ assuming a depth of $2.5 \mathrm{~m}$ and $5 \mathrm{~m}$, respectively. This vertical pressure is selected based on the depth of the pipe jacking method that is generally applied. The interruption period was 2 days. In addition, the speed at which the simulated pipe is moved is assumed to be $1.0 \times 10^{-2} \mathrm{~cm} / \mathrm{s}$, assuming the construction speed of the actual construction. The results are shown in Fig. (8). As shown in Fig. (8), when the vertical pressure is $90 \mathrm{kPa}$, it shows a comparatively large thrust compared when the vertical pressure is $45 \mathrm{kPa}$. These results show that the thrust increases due to the increase in the overburden pressure. However, even when the construction depth is deep, the thrust decreases as the addition ratio of fatty acids increases. Therefore, it became clear that thrust can be reduced by adding fatty acids regardless of the difference in construction depth. 


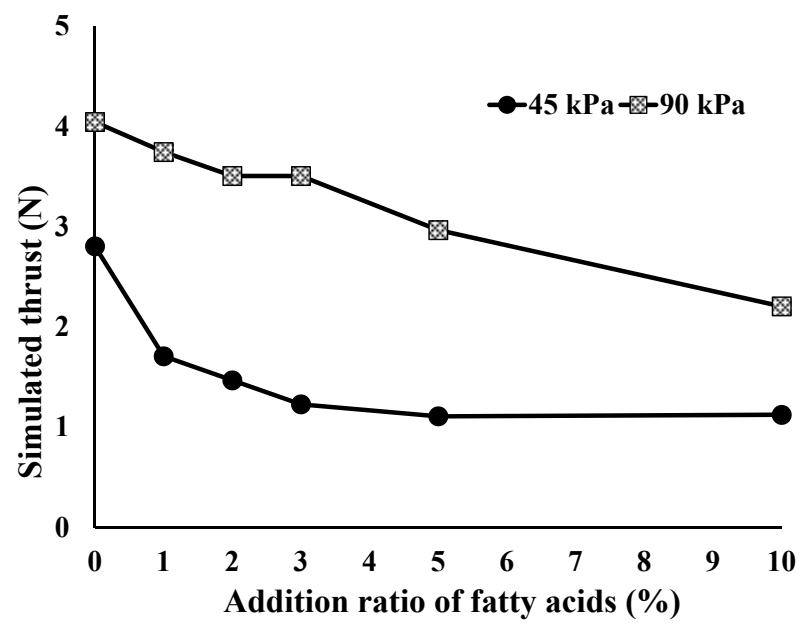

Fig. (8). Dependency of thrust from the percentage of fatty acids and vertical pressure.

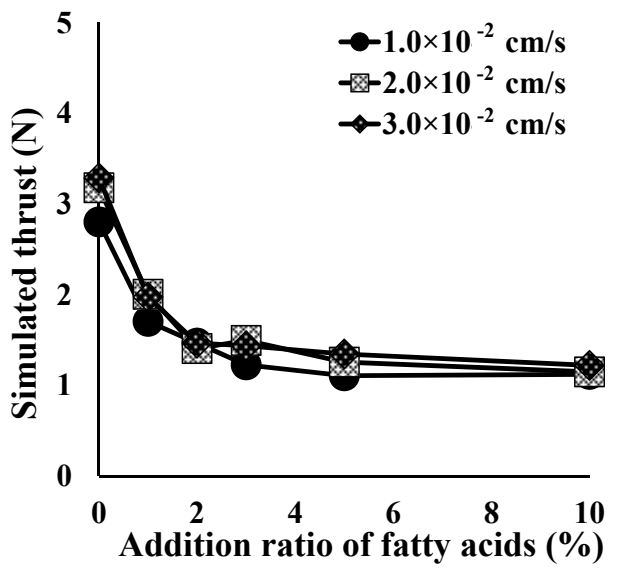

(a) Vertical pressure: $45 \mathrm{kPa}$.

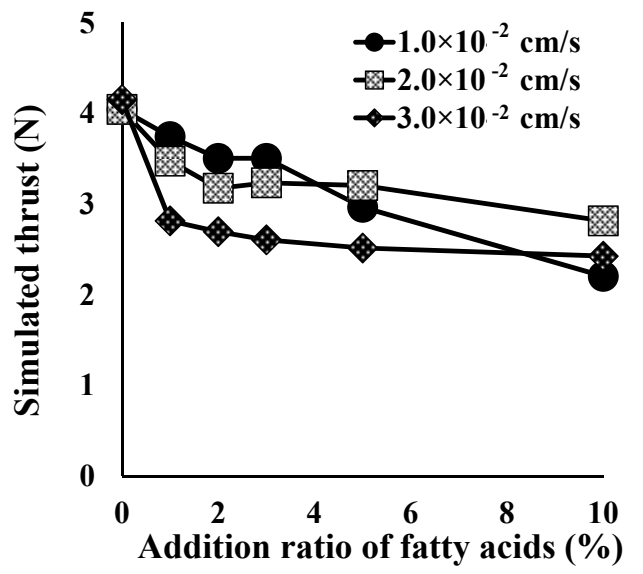

(b) Vertical pressure: $90 \mathrm{kPa}$.

Fig. (9). Dependency of thrust from the percentage of fatty acids and pipe jacking speed.

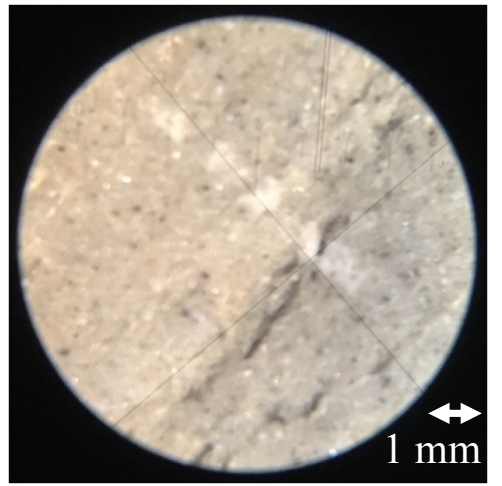

(a) $2 \%$.

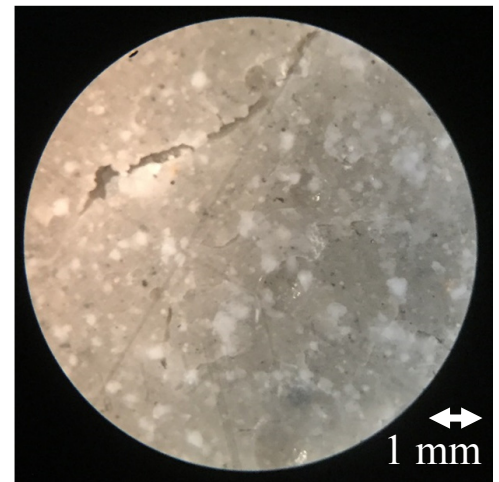

(b) $10 \%$.

Fig. (10). Contact surface of the simulated pipe (optional image).

In order to investigate the influence of the pipe jacking speed on the thrust at the resumption of construction, the test was conducted under the conditions of the pipe jacking speed of $1.0 \times 10^{-2} \mathrm{~cm} / \mathrm{s}, 2.0 \times 10^{-2} \mathrm{~cm} / \mathrm{s}$ and $3.0 \times 10^{-2} \mathrm{~cm} / \mathrm{s}$. The interruption period was 2 days. The results are shown in Fig. (9a and b). It can be seen that there is no significant difference in the trend of decrease in thrust even if it is constructed with different pipe jacking speed using the backfilling material with fatty acids.

Fig. (10a and b) show the surface images of the fatty acids 
addition ratio of $2 \%$ and $10 \%$ after the simulated pipe jacking construction test is finished. These images were taken with a microscope. By using the images, the area of fatty acids per contact surface is calculated by means of image analysis [18]. Fig. (11a and b) show the image analysis in the contact surface of the simulated pipe. It can be confirmed that the area of fatty acids is increased at $10 \%$ than at the fatty acids addition ratio of $2 \%$. It means that the surface area ratio increased with increasing fatty acids addition ratio. It is expected that the reduction of thrust can be improved when the surface area of fatty acids is largely due to their function as a lubricant.

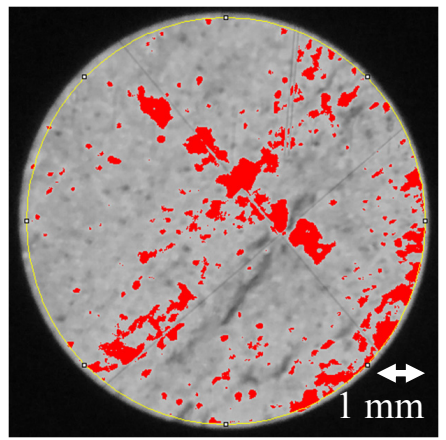

(a) $2 \%$.
The increasing rate of the thrust was calculated from the results of the test under the conditions of normal stress of 90 $\mathrm{kPa}$ and pipe jacking speed of $1.0 \times 10^{-2} \mathrm{~cm} / \mathrm{s}$ (Fig. 12). The increasing rate of the thrust was defined by equation (1). From Fig. (12), it can be seen that the increasing rate of the thrust is the smallest in any interruption period when the fatty acids addition ratio is $3 \%$. This fact means that it is possible to reduce the thrust efficiently after the resumption of construction interruption by adding 3\% of fatty acids to the conventional backfilling material.

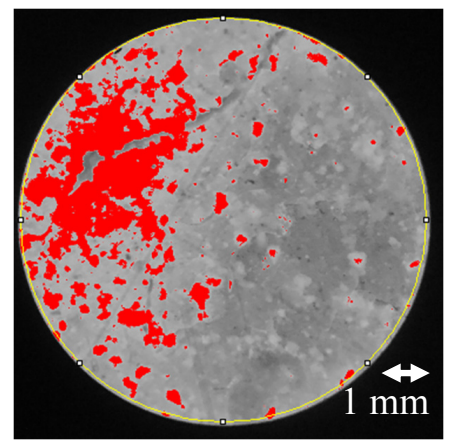

(b) $10 \%$.

Fig. (11). Relative area (colored by red) of the fatty acids on the surfaces of simulated pipes containing 2 and $10 \%$ of fatty acids.

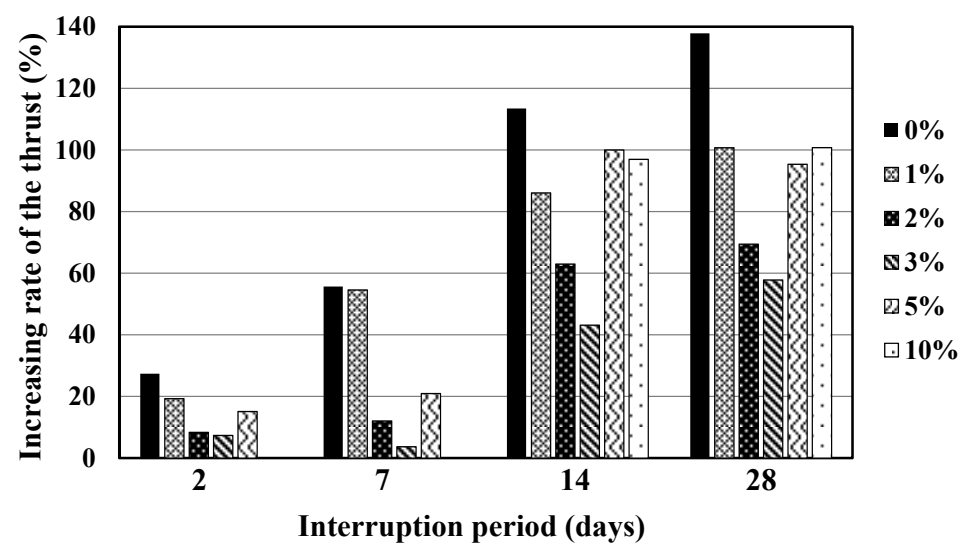

Fig. (12). Dependency of the increasing rate of the thrust from the interruption period and percentage of fatty acids.

Increasing rate of the thrust (\%)

$=\frac{\text { Simulated stress(After interruption) }- \text { Simulated stress (0day) }}{} \times 100$ Simulated stress (0day)

\section{CONCLUSION}

The lubricants play an important role in reducing the friction during pipe jacking. In this research, the improvement of lubrication performance for pipe jacking was investigated by adding fatty acids into a conventional backfilling material. As a result of the bleeding test, the bleeding rate decreases with the increase in addition ratio of the fatty acids while the shrinkage of the backfilling material is suspected due to the absorption of water from the pipe when the excess fatty acids are added into the backfilling material. Based on the results of the direct shear test, the thrust can be reduced by adding $2 \%$ or more fatty acids into the backfilling material regardless of the difference in construction depth while there is no significant difference of decrease in thrust due to the pipe jacking speed. Additionally, it was found that it was possible to reduce the thrust after resuming the construction of pipe jacking by adding 3\% of fatty acids as the backfilling material.

\section{CONSENT FOR PUBLICATION}

Not applicable.

\section{AVAILABILITY OF DATA AND MATERIALS}

The data used to support the findings are available from corresponding author $[$ A.H] upon request. 


\section{FUNDING}

None.

\section{CONFLICT OF INTEREST}

The authors declare no conflict of interest, financial or otherwise

\section{ACKNOWLEDGEMENTS}

Declared none.

\section{REFERENCES}

[1] Japanese Geotechnical Society, From research and design to construction in pipe jacking method., Japanese Geotechnical Society: Tokyo, 1997, pp. 1-32.

[2] Ministry of Land, "Infrastructure, Transport and Tourism", In: Land, Infrastructure, Transport and Tourism White Paper PDF, Ministry of Land, Infrastructure, Transport and Tourism: Tokyo, 2016.

[3] Japan Pipe Jacking Technology Association, Pipe jacking system (Pipe jacking technology edition)., Japan Pipe Jacking Technology Association: Tokyo, 2010.

[4] N. Takane, Pipe Jacking Method., Morikita Publishing Co., Ltd: Tokyo, 1982.

[5] T. Nanno, Design and construction in pipe jacking method., Morikita Publishing Co., Ltd: Tokyo, 1989.

[6] T. Sato, "The study on the influence to the surrounding ground of the pipe roof method using the pipe jacking method", Ph.D. thesis., Kyushu University, Fukuoka, Japan, 2012.

[7] K. Yoshida, Long term stop in pipe jacking construction due to obstacles -Trouble factor and coping method, vol. 30. Monthly magazine of microtunneling: Tokyo, 2016, pp. 23-24

[8] A.L. Pellet-Beaucour, and R. Kastner, "Experimental and analytical study of friction forces during microtunneling operations", Tunn. Undergr. Space Technol., vol. 17, pp. 83-97, 2002.

[http://dx.doi.org/10.1016/S0886-7798(01)00044-X]

[9] X. Yang, Y. Liu, and C. Yang, "Research on the Slurry for LongDistance Large-Diameter Pipe Jacking in Expansive Soil", Adv. Civ. Eng., 2018.

[http://dx.doi.org/10.1155/2018/9040471]

[10] K. Shou, J. Yen, and M. Liu, "On the frictional property of lubricants and its impact on jacking force and soil-pipe interaction of pipejacking", Tunn. Undergr. Space Technol., vol. 25, pp. 469-477, 2010. [http://dx.doi.org/10.1016/j.tust.2010.02.009]

[11] C.C. Reilly, and T.L.L. Orr, "Physical modelling, of the effect of lubricants in pipe jacking", Tunn. Undergr. Space Technol., vol. 63, pp. 44-53, 2017.

[http://dx.doi.org/10.1016/j.tust.2016.11.005]

[12] H. Shimada, Y. Yoshida, and A. Hamanaka, "T, Sasaoka, K. Matsui "By-functional Material of Lubrication and Backfilling for Pipe Jacking”", Curr. Adv. Civ. Eng., vol. 2, pp. 68-73, 2014.

[13] T. Doi, and M. Ino, Slow act of backfilling material suitable for pipe jacking method., vol. 26. Monthly magazine of microtunneling: Tokyo, 2012, pp. 35-39.

[14] Y. Totani, Characteristics and applications of oils and fats., Saiwai shobo: Tokyo, 2012

[15] ASTM International, Standard Test Methods for Measurement of Hydraulic Conductivity of Saturated Porous Materials Using a Flexible Wall Permeameter, vol. 26, ASTM D5084-03.

[16] K. Ishigaki, K. Kurumisawa, and T. Nawa, "The Effects of Bleeding on the Microstructure of Hardened Cement Paste", Cem. Sci. Concr. Technol., vol. 66, pp. 111-118, 2012.

[http://dx.doi.org/10.14250/cement.66.111]

[17] Japan Hume Pipe Association, Technical document hume pipe design and construction manual., Japan Hume Pipe Association: Tokyo, 2013.

[18] Otago Center for Confocal Microscopy, https://www.otago.ac.nz/omni/confocal-microscopy/cm-image-analysi s.html\#fijiimagej

\section{(C) 2019 Maehara et al.}

This is an open access article distributed under the terms of the Creative Commons Attribution 4.0 International Public License (CC-BY 4.0), a copy of which is available at: https://creativecommons.org/licenses/by/4.0/legalcode. This license permits unrestricted use, distribution, and reproduction in any medium, provided the original author and source are credited. 